\title{
Efficient use of electric energy in homes through multi-agent systems, case study Monterrey N.L., Mexico
}

\section{Uso eficiente de la energía eléctrica en los hogares mediante sistemas multi-agente, caso de estudio Monterrey N.L., México}

\author{
RAMOS-NOLAZCO, Jesús Alejandro†", SILVA-AVILA, Alicia Elena', CASTORENA-PEÑA, Jesús \\ Abraham' and BRENA-PINERO, Ramón Felipe"'
}

'Universidad Autónoma de Coahuila. Barranquilla s / n, Col. Guadalupe C.P. 25750. Mexico.
"Tecnológico de Monterrey, School of Engineering and Sciences, C. P. 2501. Mexico.

ID $1^{\text {st }}$ Author: Jesús Alejandro, Ramos-Nolzaco / ORC ID: 0000-0002-0901-5255, CVU CONACYT ID: 511119

ID $1^{\text {st }}$ Coauthor: Alicia Elena, Silva-Avila / ORC ID: 0000-0001-7093-9898, CVU CONACYT ID: 260461

ID $2^{\text {nd }}$ Coauthor: Jesús Abraham, Castorena-Peña / ORC ID: 0000-0002-8833-1159, CVU CONACYT ID: 411532

ID $3^{\text {rd }}$ Coauthor: Ramón Felipe, Brenda-Pinero / ORC ID: 0000-0002-0995-2273

DOI: $10.35429 / J A D .2020 .12 .4 .11 .24$

Received July 15, 2020; Accepted December 30, 2020

\begin{abstract}
This article presents an experimental research whose objective is to verify through experimentation if the systems for air conditioning and lighting homes based on the use of MultiAgent Systems (MAS) are more efficient than traditional systems in terms of perceived environmental comfort. by people and the electricity cost generated. The proposed methodology involved the development of a housing simulator, the definition of the "environmental comfort" variable, the description of the evaluated lighting and air conditioning systems, and the definition of the proposed experiments based on independent variables that could impact on the performance of the aforementioned systems. Based on the data obtained when conducting the experiments and taking the homes in the Monterrey Metropolitan Area as a case study, it could be observed that the use of MAS is a very good alternative to reduce the consumption of electrical energy in homes taking care of not sacrificing people's comfort, thus helping to reduce the ecological impact generated by electricity generation.
\end{abstract}

Domestic electricity consumption, Multi-Agent System (MAS), Contract Network Protocol, Efficiency, Social Welfare, Simulation

\begin{abstract}
Resumen
El presente artículo presenta una investigación de tipo experimental cuyo objetivo es comprobar mediante la experimentación si los sistemas para climatizar e iluminar las viviendas basados en el uso de Sistemas Multi-Agente (MAS) son más eficientes que los sistemas tradicionales en términos del confort ambiental percibido por las personas y el gasto eléctrico generado. La metodología propuesta implicó el desarrollo de un simulador de viviendas, la definición de la variable de "confort ambiental", la descripción de los sistemas de iluminación y climatización evaluados, y la definición de los experimentos propuestos con base en variables independientes que puedan impactar en el desempeño de los sistemas mencionados. Con base en los datos obtenidos al realizar los experimentos y tomando como caso de estudio las viviendas en la Zona Metropolitana de Monterrey, se pudo observar que el uso de MAS es una muy buena alternativa para reducir el consumo de energía eléctrica en los hogares cuidando de no sacrificar el confort de las personas, contribuyendo así a reducir el impacto ecológico generado por la generación de electricidad.
\end{abstract}

Consumo eléctrico doméstico, Sistema Multi-Agente (MAS), Protocolo de Red de Contratos, Eficiencia, Bienestar Social, Simulación

Citation: RAMOS-NOLAZCO, Jesús Alejandro, SILVA-AVILA, Alicia Elena, CASTORENA-PEÑA, Jesús Abraham and BRENA-PINERO, Ramón Felipe. Efficient use of electric energy in homes through multi-agent systems, case study Monterrey N.L., Mexico. Journal Architecture and Design. 2020. 4-12:11-24.

$\doteqdot$ Researcher contributing as first author. 


\section{Introduction}

The last official annual report with data from 2017, placed the domestic sector as the second with the highest consumption in the country with $27.4 \%$ of the 200,114 Gwh generated, only below the medium-sized company (Ministerio de Energía, Mexico, 2010). Despite the slight drop that the domestic sector could present in 2033, its consumption would continue to represent $23 \%$, almost on a par with large industry with $25.5 \%$ (Centro Nacional de Control de Energía, 2019).

According to Morales, Luyando and Flores (2012), the higher the economic income of the people, the greater the electricity consumption, which exposes a difficulty for people to regulate their consumption in a rational way.

Demand-side management (DSM) in smart grids allows grid customers to autonomously make reasoned decisions about their energy consumption (Fioretto, 2017). To implement demand management at the housing level, various authors such as Brena (2015), Wang (2019) and Denysiuk (2020) agree that the use of Multi-Agent Systems (MAS) is an efficient solution to improve consumption of electrical energy in homes.

In the research carried out by Suástegui (2014), the importance of people being able to constantly monitor the electricity consumption in their homes with the help of technology is pointed out, which helps to reduce unnecessary expenses, making people more aware from the point of view of economic view, even when it seems that this solution implies the sacrifice of comfort related specifically to the temperature of your houses. It is common that the inhabitants of a house do not always agree on the amount of comfort they are willing to sacrifice to reduce economic spending, as proof of this, the same research showed that $39 \%$ of the households analyzed had an oversizing in their equipment air conditioning.
Taking the work of the previous authors as a reference, the objective of this research is to check if a Multi-Agent System (MAS) is capable of controlling lighting and temperature in homes in a more efficient way than control methods traditional; understanding by efficiency, the relationship between economic comfort and environmental comfort perceived by the inhabitants of the house during a billing period of the electric service.

To verify the effectiveness of the proposed solution, the document presents an experimental methodology based on the simulation of a house with people who carry out activities in the different rooms and with objects that, when activated, cause the variation of the light and the temperature of the rooms such as: spotlights, fans, air conditioners, doors, windows and blinds. In each experiment, the characteristics of the groups of people living in the house (each with different preferences) and the control method of the objects in the house used will be modified, one of them being a Multi-Agent System. At the end of the experiments: the electricity consumption generated by the control method and the comfort achieved by the inhabitants will be compared based on the lighting and the temperature of the rooms in which they were.

The methods against which the MAS is compared will be named as "Manual" to that mechanism in which people have to operate the objects of the house themselves; while the "Automatic" mechanism will be one in which people use electrical appliances that turn on autonomously with basic reactive control such as air conditioners and spotlights activated by presence sensors. In the automatic control, the doors and windows remain closed with some variations, as normally happens in homes due to people's carelessness. 
After the present introduction, Section 2 of the article addresses the current panorama of the operation and characteristics of Multi-Agent Systems (MAS); Section 3 describes the methods and materials necessary to implement and analyze the operation of the MAS, as well as the comparison against traditional methods to adjust the light and temperature conditions of the home; Section 4 presents the results and analysis of the information obtained from the experiments; and finally, in Section 5 it will be determined if the MAS can be considered as a good option to make the expenditure of electricity in households more efficient.

\section{State of the art}

\section{Multi-Agent Systems}

The "agent" is called the computational entity (software program or robot) that according to Stuart Russell and Peter Norvig (2009) must function autonomously, perceive its environment, persist for a long period of time, adapt to changes, create and achieve goals. The agent is said to be rational when he acts in order to obtain the best result, or the best expected result in the event of uncertainty. Mas (2005) mentions that an agent is a system capable of acting independently in favor of a user or owner and at present they are used to represent real users in virtual environments.

In accordance with the above, it is established that a Multi-Agent System (MAS) is made up of 2 or more independent agents, each one performing a specific task and communicating to exchange information and / or build the final solution to a problem. In these systems, the behavior patterns of the agents can be based on cooperation or competition, for both cases, the agents have roles and require acting under interaction protocols that are patterns for the exchange of messages.

Coelho, Cohen, Guimaraes, Coelho \& Liu (2017) argue that the MAS paradigm has been advocated as a useful and promising tool for a wide range of applications, for example: Wang et al developed a multi-agent system to collectively minimize the cost of electric power and the delay in the use of appliances. In such a system, agents collectively optimize their own interests; meanwhile, the overall optimal solution is achieved.
Among other uses are those that help control smart energy grids, for example: Celik (2017) uses an MAS to model entities (homes and aggregators of electricity demand) in the neighborhood as agents. The aggregator agent is the supervising agent who determines the aggregate profile and dynamic price by communicating with local agents. Household agents are selfish, independent decision-makers who only focus on maximizing their own wellbeing while achieving near-optimal performance in the Nash equilibrium of a formulated non-cooperative coordination game.

\section{Decisions of Agents based on Profit}

Wooldridge (2009) determines the utility as a numerical value that represents how good is the state in which an agent is, the higher the utility, the better the state. Optimality in rational agents consists in maximizing the expected utility by executing the appropriate actions.

In the case of agents that seek to maximize people's comfort, the utility of an agent would be greater if it manages to make a person have the desired lighting or temperature, and the utility will be less if the temperature or lighting values are far from the desired.

\section{Pareto Efficiency and Optimality}

In "Economic Development" (Todaro, 2014), the concept of "efficiency" (in terms of consumption) is defined as the allocation of expenses that maximize consumer satisfaction or utility. One economic system is said to be more efficient than another (in relative terms) if it provides more goods and services for society using the same economic resources.

In a distribution of resources within a competitive economy, Vilfredo Pareto establishes that an allocation of resources is efficient if:

There is no other allocation of resources capable of increasing the production of one good without reducing the production of another.

- Total production cannot be reallocated to generate a higher level of welfare, without reducing the welfare of some agent. 
This condition is known as Pareto Optimality (Ayala, 2004). Transferring this condition to the study of the allocation of resources in homes, it can be said that in a room where there are two or more people, an efficient situation will be reached when none of the people can improve their situation without another person having to worsen yours.

\section{Social welfare}

Social Welfare is the sum of the payments or profits of all the agents in a given solution. Social welfare "measures" or "determines" the degree of global welfare of the agents. Welfare maximizing solutions are a subset of Pareto efficient solutions.

Abram Bergson introduced, in 1938, the social welfare function. What has been called a Bergson-Samuelson function is a function that takes the form $\mathrm{W}=\mathrm{W}(\mathrm{U} 1, \mathrm{U} 2, \ldots, \mathrm{UH})$ such that the welfare of society denoted as $\mathrm{W}$ is simply a function of the profits of its constituent members.

One of the social welfare functions considered in economics especially in the classification of income distribution is known as "Bernoulli-Nash", its value increases when the differences between the profits of the agents or people decrease; its result is the product of each of the group members' profits (Nguyen et. al., 2013). As mentioned above, this requires that the plan being evaluated represents a Pareto Optimal point, that is, that there is no other plan that improves the utility of all interested agents. The benefit that this function represents over others is that it reaches a social optimum point.

\section{Coordination of agents through the contract network protocol}

In SMAs, the communication protocols represent the patterns that shape the possible communications of their agents. One of the protocols standardized by the Foundation for Intelligent Physical Agents (FIPA) for agentbased systems is the Contract Network Protocol or CNP for its acronym in English (Singh, 2010), which is a variation of the original pattern proposed by Smith (1980).
In this protocol, an agent assumes the role of administrator who wants a task to be executed by one or more agents, who in turn send proposals to the administrator to carry out the task. Both the administrator and the possible contractors establish conditions. The administrator makes the decision on which contractor or contractors will perform the task, seeking to optimize a function that characterizes the task based on cost, time, or other unit of measure. The administrator makes the decision about which contractors will carry out the task, seeking to optimize a function that characterizes the task based on cost, time or other unit of measure.

\section{Methodology}

As mentioned in the introduction, the objective of this research is to check if a Multi-Agent System is capable of autonomously and more efficiently controlling doors, windows, blinds and electrical appliances in a home to illuminate and air-condition houses, compared to traditional methods.

To achieve the objective, it is proposed to carry out an experimental investigation in which the behavior of the different control mechanisms can be observed, generating different levels of comfort in people based on the preferences of each one, as well as different amounts of consumption of electrical energy. The relationship between the comfort obtained and the economic expenditure generated will indicate whether the MAS as a proposed method is more efficient.

Due to the complexity required to carry out these experiments in real life, it was decided to carry out the experiments in a simulator that allows modeling the environment of different houses and that, in addition, allows modeling the behavior of different control methods to illuminate and air-condition them.

To limit the scope of the experiments, it has been decided to take the Monterrey Metropolitan Area as a case study, since this area is the one that generates the greatest demand in the Northeast region of Mexico, and that region is one of the three with higher annual electricity consumption (National Center for Energy Control, 2019). 
The details of the methodology are described below in the following sections:

Development and implementation of the housing simulator to have an appropriate environment that allows testing.

- Description of the variables of interest in this research.

Definition of the methods to illuminate and control the dwellings to be compared.

Description of the experiments to be carried out.

- $\quad$ Execution and collection of results.

\section{Development and implementation of the housing simulator}

A simulator implemented on NetLogo has been used, which is an integrated development environment for agent-based modeling. In this simulator, the researcher can configure any dwelling they want using agent blocks that can represent different objects in a dwelling. Table 1 shows the different types of agents that are part of the simulation.

\begin{tabular}{|c|c|c|c|}
\hline Type & State & Actions & Consumption \\
\hline $\begin{array}{l}\text { Structural } \\
\text { (Ceiling or } \\
\text { Wall) }\end{array}$ & $\begin{array}{l}\text { Does not } \\
\text { change } \\
\text { state }\end{array}$ & $\begin{array}{l}\text { Transfer heat to } \\
\text { the interior or } \\
\text { exterior } \\
\text { depending on } \\
\text { their physical } \\
\text { characteristics } \\
\text { and the } \\
\text { environment } \\
\text { that surrounds } \\
\text { them }\end{array}$ & Null \\
\hline \multirow[t]{2}{*}{ Door } & Open & $\begin{array}{l}\text { Transfer heat } \\
\text { by conduction }\end{array}$ & Null \\
\hline & Closed & $\begin{array}{l}\text { Transfer heat } \\
\text { by convection }\end{array}$ & Null \\
\hline \multirow{4}{*}{$\begin{array}{l}\text { Window } \\
\text { System - } \\
\text { Blind. } \\
\text { (Material } \\
\text { combination, } \\
\text { glass and } \\
\text { PVC are } \\
\text { assumed) }\end{array}$} & $\begin{array}{l}\text { Closed } \\
\text { window } \\
\text { Shutter } \\
\text { closed }\end{array}$ & $\begin{array}{l}\text { Transfer heat } \\
\text { by conduction }\end{array}$ & Null \\
\hline & $\begin{array}{l}\text { Closed } \\
\text { window } \\
\text { Open } \\
\text { Shutter } \\
\end{array}$ & $\begin{array}{l}\text { Transfer heat } \\
\text { by conduction }\end{array}$ & Null \\
\hline & $\begin{array}{l}\text { Open } \\
\text { window } \\
\text { Shutter } \\
\text { closed }\end{array}$ & $\begin{array}{l}\text { Transfer heat } \\
\text { by conduction }\end{array}$ & Null \\
\hline & $\begin{array}{l}\text { Open } \\
\text { window } \\
\text { Open } \\
\text { Shutter }\end{array}$ & $\begin{array}{l}\text { Transfer heat } \\
\text { by convection } \\
\text { (through air) }\end{array}$ & Null \\
\hline
\end{tabular}

\begin{tabular}{|c|c|c|c|}
\hline \multirow[t]{2}{*}{ Fan } & $\begin{array}{l}\text { Switched } \\
\text { on }\end{array}$ & $\begin{array}{l}\text { Modify Wind } \\
\text { Speed, } \\
\text { Consume } \\
\text { Current }\end{array}$ & $0.1 \mathrm{kWh}$ \\
\hline & Off & None & Null \\
\hline \multirow[t]{3}{*}{$\begin{array}{l}\text { Air } \\
\text { conditioner }\end{array}$} & $\begin{array}{l}\text { Switched } \\
\text { on }\end{array}$ & $\begin{array}{l}\text { Remove Heat, } \\
\text { Modify Wind } \\
\text { Speed, } \\
\text { Consume } \\
\text { Current }\end{array}$ & $1.8 \mathrm{kWh}$ \\
\hline & Resting & $\begin{array}{l}\text { Modify Wind } \\
\text { Speed, } \\
\text { Consume } \\
\text { Current }\end{array}$ & $0.1 \mathrm{kWh}$ \\
\hline & Off & None & Null \\
\hline \multirow[t]{2}{*}{ Spotlight } & $\begin{array}{l}\text { Switched } \\
\text { on }\end{array}$ & $\begin{array}{l}\text { Bring Light, } \\
\text { Bring Heat, } \\
\text { Consume } \\
\text { Power }\end{array}$ & $0.1 \mathrm{kWh}$ \\
\hline & Off & None & Null \\
\hline
\end{tabular}

Table 1 Objects available in the simulator to configure the houses

Source: Own elaboration

The simulator also allows you to configure agents to represent the people of the house, on these agents and to simulate different scenarios, you can configure the properties that appear in Table 2.

\begin{tabular}{|c|c|}
\hline Property & Description of your values \\
\hline $\begin{array}{l}\text { Desired temperature } \\
\text { and light levels, } \\
\text { expressed in degrees } \\
\text { Celsius }\left({ }^{\circ} \mathrm{C}\right)\end{array}$ & $\begin{array}{l}\text { - Minimum: Minimum amount of } \\
\text { temperature that the person could } \\
\text { tolerate. } \\
\text { Desired: Appropriate temperature } \\
\text { with which the person would be } \\
\text { totally satisfied. } \\
\text { Maximum: Minimum amount of } \\
\text { temperature that the person could } \\
\text { tolerate. }\end{array}$ \\
\hline $\begin{array}{l}\text { Desired light levels, } \\
\text { expressed in lumens } \\
(\mathrm{lm})\end{array}$ & $\begin{array}{l}\text { - Minimum: Minimum amount of } \\
\text { light required to carry out your } \\
\text { activities. } \\
\text { - Desired: Appropriate amount of } \\
\text { light to carry out your activities. } \\
\text { - Maximum: Maximum amount of } \\
\text { light that the person can tolerate. }\end{array}$ \\
\hline Desired spending & $\begin{array}{l}\text { Equivalent to the budget you have for the } \\
\text { payment of electricity service during a } \\
\text { two-month period. }\end{array}$ \\
\hline Roles & $\begin{array}{l}\text { - Adult } 1 \text { (Over } 30 \text { years old with } \\
\text { activities related to work outside } \\
\text { the home) } \\
\text { Adult } 2 \text { (Over } 30 \text { years old with } \\
\text { activities related to the home) } \\
\text { - Student } 1 \text { (Between } 4 \text { to } 12 \text { years } \\
\text { old with school activities and little } \\
\text { activity outside the home). } \\
\text { Student } 2 \text { (Between } 13 \text { to } 25 \text { years } \\
\text { old with school activities and with } \\
\text { more activity outside the home) }\end{array}$ \\
\hline Schedule & $\begin{array}{l}\text { Distribution of activities according to the } \\
\text { role chosen for the agent. According to } \\
\text { the activity, the simulator places the agent } \\
\text { in one of the rooms or outside the house. }\end{array}$ \\
\hline
\end{tabular}

Table 2 Configuration of properties of the agents that simulate people

Source: Own elaboration 
The simulator executes a cyclical process of calculating variables based on the states of the appliances and structural elements drawn in the program, as well as the state and location of the inhabitants of the home; each iteration of the process equals 1 minute in time. The process stops after 2 months (30 days), or 86,400 cycles. sections:

The developed tool contains two main

First section, Observation of the environment (Figure 1): Shows the distribution of the rooms of the study case, of the electrical appliances, doors and windows that can be configurable to represent different scenarios. The section also shows the location and activities of the inhabitants of the home at a certain time of day, as well as the outdoor weather conditions of temperature, wind and amount of light.

- Second section, Graphical behavior of variables (Figure 2): This section is made up of 3 main graphs in which it is possible to visualize:

- The behavior of the temperature during each minute of the experiment in each room of the house. It can be set to observe the amount of light.

- The second graph shows in yellow the total $\mathrm{kWh}$ consumed at each moment, and in green the billing cost reached up to the same minute based on the Rate used in the simulation.

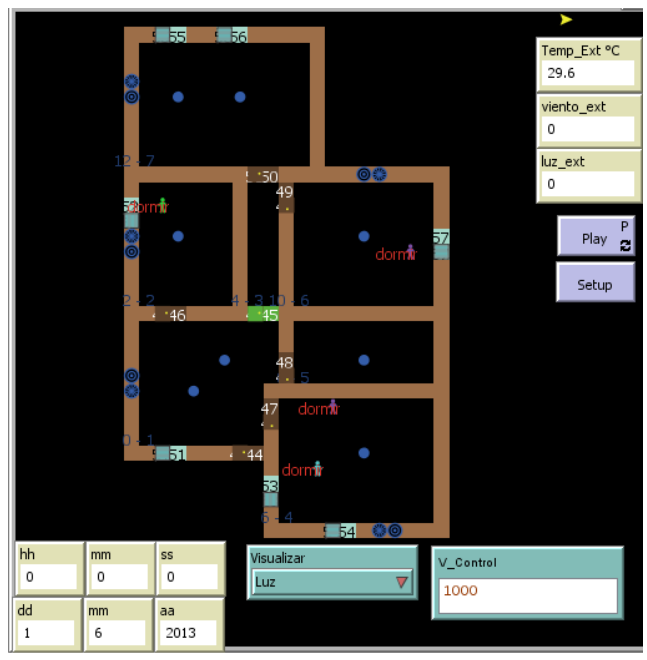

Figure 1 First section, observation of the environment Source: Own elaboration

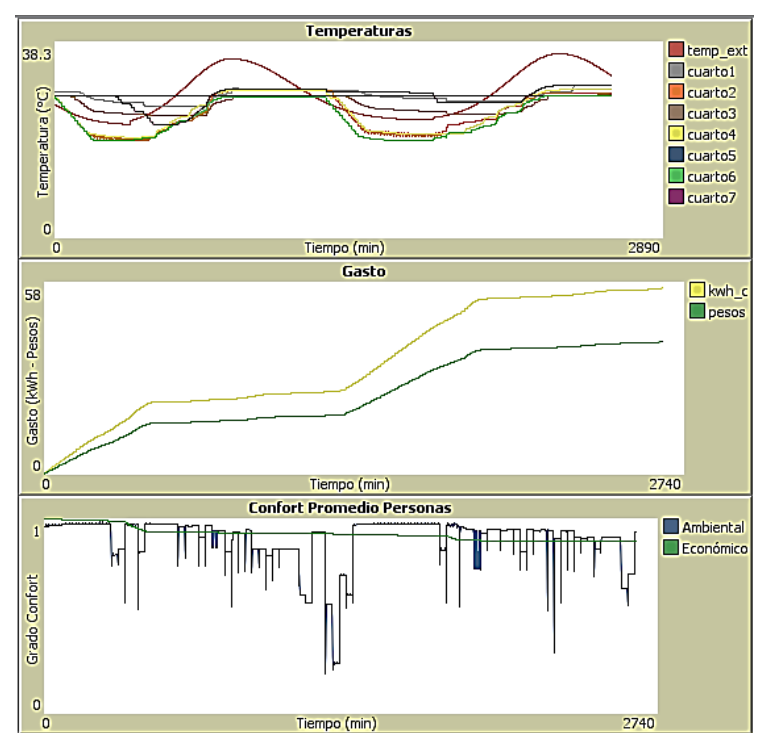

Figure 2 Graphical behavior of variables Source: Own elaboration

To validate the calculations made by the simulator on the physical variables involved, measurements were made inside a house located in the City of Monterrey Nuevo León for a period of 48 hours. With all the structural objects intervening in the calculation, a maximum difference of $1.5^{\circ} \mathrm{C}$ and a mean deviation of $0.32^{\circ} \mathrm{C}$ are obtained, the latter less than that obtained by Gerlich and Zalesak (2010) in a similar simulator developed with MATLAB and COMSOL.

\section{Description of the variables of interest in the comparison of the methods}

\section{Independent variables}

The efficiency of both the proposed MAS and the other methods can be affected by different independent variables such as:

- $\quad$ The number of inhabitants in the home.

The temperature levels desired by the different inhabitants of a home.

- The amount of money that the inhabitants would like to invest in electricity (Mexican pesos).

Therefore, these variables will be modified in the experiments to observe and compare the performance of the methods in the different situations proposed. 


\section{Dependent variables}

On the other hand, since the way to measure the efficiency of the methods is through the comfort achieved by the people and the expense that was required, it is necessary to define the way in which said environmental comfort will be measured.

We will base this term on some objective characteristics of a given space, parameters that can be analyzed independently of the user. The parameters of interest in this case are the temperature and the lighting (Table 3) perceived by the user in degrees Celsius $\left(^{\circ}\right.$ C) and Lux (Lx) respectively. The formulas to calculate the environmental comfort are the following:

$$
\operatorname{Confort}_{i T}=\left\{\begin{aligned}
0, \text { Si } & T_{s} \leq T_{\min } \\
\frac{T_{s}-T_{\min }}{T_{d}-T_{\min },} \text { Si } & T_{\min }<T_{s}<T_{d} \\
\frac{T_{\max }-T_{s}}{T_{\max }-T_{d},} \text { Si } & T_{d} \leq T_{s}<T_{\max } \\
0, S i & T_{s} \geq T_{\max }
\end{aligned}\right.
$$

Where Confort $_{i T}$ refers to the level of comfort that person "i" feels with respect to the temperature of the room. Where $\mathrm{T}_{\mathrm{s}}$ refers to the temperature perceived by the person " $\mathrm{i}$ ", $\mathrm{T}_{\mathrm{d}}$ is the temperature desired by the person and finally $T_{\min }$ and $T_{\max }$ are the minimum and maximum temperatures tolerated by the person.

$$
\text { Confort }_{i L}=\left\{\begin{array}{rll}
0, & \text { Si } & L_{s} \leq L_{\min } \\
\frac{L_{s}-L_{\min }}{L_{L-L_{\min }}}, & \text { Si } & L_{\min }<L_{s}<L_{d} \\
\frac{L_{\max }-L_{s}}{L_{\max }-L_{d},}, & S i & L_{d} \leq L_{s}<L_{\max } \\
0, & S i & L_{s} \geq L_{\max }
\end{array}\right.
$$

As in the previous equation, Confort ${ }_{i L}$ refers to the level of comfort that person "i" feels according to the lighting in the room. The variables $L_{s}, L_{d}, L_{\min }$ and $L_{\max }$ refer to the lighting levels: sense (perceived), desired, minimum and maximum.

We observe that as it is characteristic of the Membership functions, the value of Confort $_{i \mathrm{~T}}$ and Confort ${ }_{\mathrm{iL}}$ must be in a range of $[0,1]$.

Finally, the level of Comfort due to Environmental conditions $\left(\mathrm{C}_{\mathrm{Ai}}\right)$ reached by person " $i$ " is defined in the following equation.

$C A_{i}=\left(\alpha_{i} *\right.$ Confort $\left._{i T}\right)+\left(\beta_{i} * \operatorname{Confort}_{i L}\right)$
Where $\alpha_{i}$ and $\beta_{i}$ are the coefficients that represent the level of preference of the person "i" towards the variables temperature and lighting respectively, both with range $[0,1]$. The sum of these two coefficients must be equal to 1. By assigning values higher than the temperature preference coefficient over the lighting one, it will be indicating that it is more important for a person to have a suitable temperature than an appropriate lighting level.

\section{Definition of comparable methods for lighting and control of dwellings}

Since the intention is to compare the MAS against other methods for the control of classic lighting and temperature of the houses, the most relevant characteristics about the operation of each method are described below. At this point, it is worth noting that the MAS described is a proposal made by the authors of this article, so that in the future, these experiments can be replicated with other SMAs.

\section{Manual method}

By means of this method, a scenario will be simulated in which the inhabitants of the house control the ignition of electrical appliances themselves.

Morales et. to the. (2012) and Suástegui (2014) conclude that the economic income of families is a determining factor for the consumption of electrical energy, in addition, Suástegui points out that air conditioning represents the highest cost of electricity in homes.

In order to verify the above, as well as to be able to represent the sector of the population that cannot afford high consumption due to a low economic income, it has been decided to characterize this method in such a way that a minimum electricity consumption is obtained through the following rules of action:

- People are limited to the use of fans, windows, blinds and spotlights to illuminate and air condition the rooms.

- The spotlights may be used when the amount of light required to carry out an activity cannot be obtained through the opening of the blinds. 
Air conditioners may not be used at any time.

- The use of fans is allowed when the temperature level is higher than that supported by one of the inhabitants in a room and cannot be adjusted by opening windows.

Strictly, the rules of action will not be modified regardless of the comfort that is observed in the people of the different groups, the electricity cost generated, or the cost of the service until the moment of observation.

In this method, despite being characterized to obtain a minimum expenditure, there will not be a credit limit to observe the expenditure of the different groups of inhabitants by following the rules mentioned above.

\section{Automatic method}

The particular objective of this method is to provide people with the highest level of comfort possible through the use of technology in light bulbs and air conditioning devices, to adapt the light and temperature conditions without human action.

The rules of action in this method are the following:

- People are limited to the use of air conditioners and spotlights to illuminate and air-condition rooms.

The air conditioners will be on while someone is in the home.

The spotlights will automatically turn on when the presence of a person in the room is detected and the amount of light is less than that required to carry out the activity of the person.

Doors, windows, and shutters will be kept closed for most of the time of the experiment. Randomly, the status will be changed to "open" for short periods of time, in order to represent typical neglect situations in homes.
Strictly, the rules of action will not be modified regardless of the comfort that is observed in the people of the different groups, the electricity cost generated, or the cost of the service until the moment of observation.

The previous rules of action will allow emulating the situations exposed by Morales et. to the. (2012) and Suástegui (2014) about the irrational use of electrical energy in homes, with an excessive use of air conditioners in homes, all with the aim of reaching the highest levels of comfort.

As in the Manual method, there will be no credit limit to be able to observe the expenditure of the different groups of inhabitants when following the rules of this method.

\section{Systems Based Multi-Agent Method (MAS)}

This method uses Artificial Intelligence mechanisms to make the use of electricity in homes more efficient, maximizing the comfort of all inhabitants and minimizing electricity consumption.

The proposed MAS is composed of agents that interact under the Contract Network Protocol assuming 3 different roles:

Person. Represents the interest of one of the inhabitants.

Service provider. Control one of the appliances or elements of the house (door, window or blind).

Administrator. Take into account:

- $\quad$ The needs of the people in each room.

- $\quad$ The credit that people have to invest in services.

- $\quad$ The costs of available services, to choose the work plan with the agents "Service Providers" that maximizes the social welfare of the inhabitants based on the utility that the agents "Person" who are in the room can achieve. 


\section{Usefulness of the agents when using the objects of the house}

To calculate the profit that an agent "Person" would obtain from the "Service Providers" work plan, the following function is proposed:

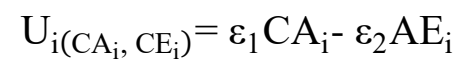

We say that $\mathrm{U}_{\mathrm{i}}\left(\mathrm{CA}_{\mathrm{i}}, \mathrm{CE}_{\mathrm{i}}\right)$ It is the utility of one of the plans created by the Administrator for the ith Person given the Environmental Comfort $\mathrm{CA}$ and the Economic Impact $\mathrm{AE}$ that this plan provides according to the cost of this.

Since there are currently people who prefer comfort rather than looking after the economy or vice versa, the coefficients $\varepsilon_{-} 1$ and $\varepsilon \_2$ with rank $[0,1]$ represent the level of importance that the Person gives to each of the variables. In this case, the result of the sum of the coefficients $\varepsilon_{-} 1$ and $\varepsilon_{-} 2$ must be 1 .

It should be noted that in this control method all simulated devices and elements in the home can be used. Although the MAS adapts by itself to the different conditions established by the independent variables of the experiment, there are two ways to influence the behavior of the MAS: the available credit of the inhabitants to spend on electrical energy and the way in which the that the MAS will be able to spend that resource by simulating the Economic Impact of humans.

\section{Agents' feeling of economic affectation}

To provide the MAS with a mechanism to make decisions about how much money the personal agents are willing to spend at each moment of the experiment, it is proposed to model the Sense of Economic Affection AE as the annoyance that a "Person" agent could feel when spending 1 unit of your credit due to the $\operatorname{cost} C_{j}$ of activating household items and the remaining credit $\mathrm{D}$, which is determined by the following equation:

$A E_{i}=\left\{\begin{array}{cll}100000 \cdot C_{j}, & \text { if } & D=0 \\ \frac{C_{j} V T}{G_{d}^{i}-G_{i}}, & \text { if } & D>0\end{array}\right.$
In this function if the available credit of a person $\left(G_{d^{-}}^{i} G_{i}\right)$ is equal to zero, the cost of activating objects will be multiplied by a value that is too high, this in order to subsequently produce a negative profit if the price of the plan is greater than zero and cannot be chosen, or else the impact will be zero if the plan has no cost.

The level of economic impact depends on the value assigned to the variable "VT" and the desired expense, when these are equal, the agents will think that the cost of the services is correct (equal to the real cost), according to the credit available decreases, concern will increase in relation to the division of these values. As can be seen in the previous function, the Administrator can know the different degree of affectation that the same plan (its cost does not change) causes each person according to the desired Expense, the expense registered up to that moment and the value assigned to VT.

At this point we must mention that the rate system used by CFE is expected to have effects on user behavior, while initially each $\mathrm{kWh}$ has the minimum price, as the consumption limits established by each rate are crossed. the value of the following $\mathrm{kWh}$ will be more expensive, therefore, $\mathrm{G}_{\mathrm{i}}$ will increase faster when each limit imposed on the CFE rates is crossed.

\section{Design of the experiments}

To know the effectiveness of the proposed solution, it is proposed to carry out two experiments using the housing simulator at the end of which it is desired to observe the amount of money that a group of inhabitants would have to pay for the amount of electrical energy consumed and the average comfort obtained during a bimester.

\section{First Experiment: imitation of current behaviors}

The first experiment consists of initially assigning to the MAS a fixed amount of available money of $\$ 1,200.00$ Mexican pesos distributed equally among the inhabitants of the house, taking as a reference the consumer attitudes of the Monterrey Metropolitan Area (ZMM) reflected in the study by Morales et al. (2015). 
With this particularity of the experiment, different scenarios will be run varying the characteristics of the inhabitants shown in the study groups described later within the specification of the study case.

The experiment should be repeated with the 3 control methods proposed in this investigation to compare the results: MAS, Manual and automatic.

\section{Second Experiment: adaptation and improvement of the MAS}

As a second experiment, it is proposed to observe the results of the previous experiment and take the value of the expenditure obtained by the best method in those cases where the MAS has not been able to exceed the efficiency.

Once the amount to spend available for the MAS has been modified, it will be divided equally among the members of the group and they will run the scenarios again to see if the MAS is capable of achieving better efficiency when receiving more specific rules from the the inhabitants of the house.

\section{Case study}

As mentioned at the beginning of the Methodology, the research will focus on the study of homes located in the Metropolitan Area of Monterrey (ZMM), which is why the simulator proposed for the experiments will be fed with the records of the meteorological station 763940 (MMAN, Latitude: 25.86, Longitude: -100.38, Altitude: 448) located at the Monterrey International Airport, Nuevo León. (Tutiempo Network, S.L., 2015).

People's behavior will be based on the National Survey on Time Use (National Institute of Statistics and Geography, 2014).

In the ZMM the rates applied by the Federal Electricity Commission are: 1C, 1D, 1E and $1 \mathrm{~F}$, therefore, they are the ones that will be taken into account to calculate the amount of money that the group of inhabitants would pay at the end of the simulation of a two-month period.
The average size of households in the $\mathrm{ZMM}$ is 4 inhabitants according to the last Population and Housing Census (INEGI, 2010), therefore, there may be discrepancies between the level of lighting and temperature preferred by each person, as well as between the budget that each one has to pay for the service.

Based on the above, for this research 6 different study groups are proposed where different types of people are represented, which are described in Table 3 . The Table records the importance that each person gives to both lighting and to temperature, adding one unit between both variables; The same is true when deciding what would weigh the most in your decisions about comfort and power consumption. The data expressed in the Table were randomly generated, seeking to represent the diversity of groups of inhabitants of the City of Monterrey.

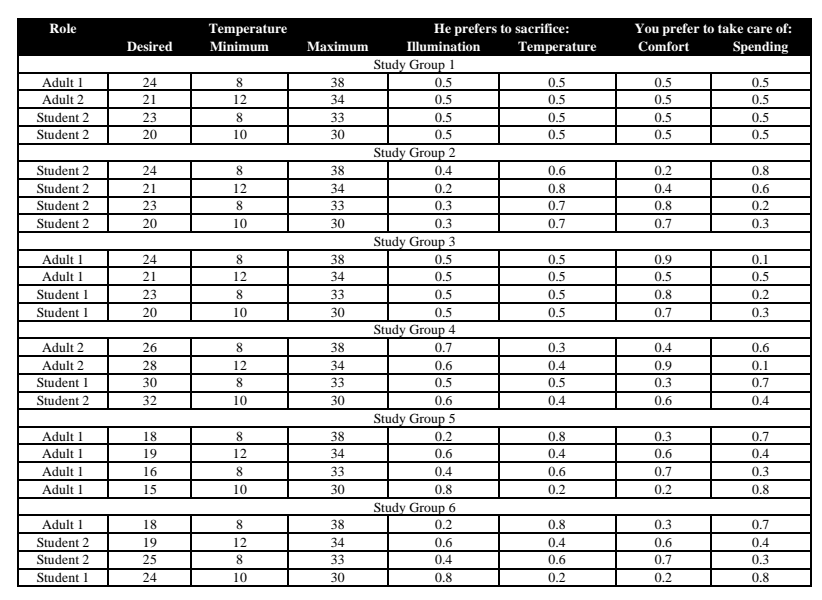

Table 3 Study groups for the simulation of people in the house

Source: Own elaboration

\section{Execution and collection of results}

\section{Results of the first experiment: Imitation of current behaviors}

Table 4 below presents the results obtained in the first experiment. For each case, the method with the best result in terms of method efficiency is highlighted with "*".

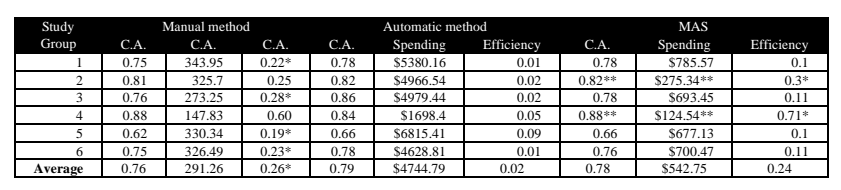

Table 4 Comparison between Manual, Automatic and MAS control methods (* Represents the method with the highest efficiency, ** Optimal values of the experiment) Source: Own elaboration 
When comparing the results, we can see that the MAS achieved an average comfort $1 \%$ lower than the Automatic method, however, it is much more efficient.

On the other hand, when comparing the MAS with the manual method, we can observe an increase in comfort of $1 \%$ but a decrease in efficiency due to a greater use of electrical energy.

In this experiment, only two cases can be observed in which one of the methods was the optimal of the 3 and occurred in study groups 2 and 4, both with the MAS, since there is no other method that offers an improvement so much of Environmental Comfort and Expense.

\section{Results of the second experiment: adaptation and improvement of the MAS}

The results of the second experiment appear in Table 5. Since the only method that obtained greater efficiencies in the different study groups was the Manual method, the results of the Automatic method no longer appear in the Table.

It is necessary to remember that the resource available to spend by the MAS was obtained from the expense generated by the Manual method in the previous experiment.

In this experiment, it is observed that when modifying the resource available to spend from the MAS, its efficiency was greater than that of the manual method in all cases and, in the same way, the expenditure was lower in the MAS in all cases.

It should also be noted that the MAS manages to achieve Pareto Optimality in $66 \%$ of the cases with respect to the Manual method (double with respect to the previous experiment) and in $100 \%$ of the cases with respect to the Automatic method as already stated. had also observed from the previous experiment.

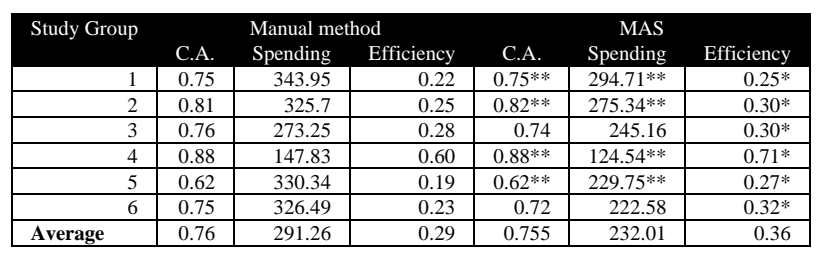

Table 5 Second comparison between MAS with parameter adjustment and Manual method (* Represents the method with the highest efficiency, ** Optimal values of the experiment)

Source: Own elaboration

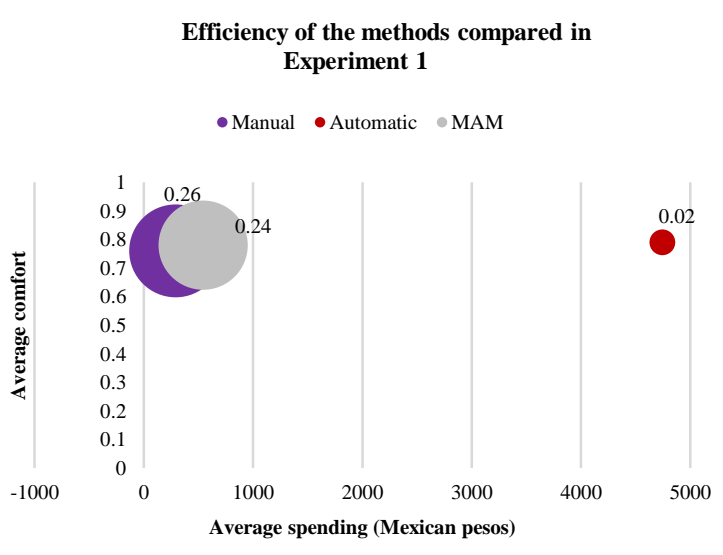

Graphic 1 Comparison between control methods Source: Own elaboration

\section{Analysis and discussion of results}

As mentioned at the beginning of the document, the purpose of this experiment has been to observe if a MAS helps to consume electrical energy in homes more efficiently than the traditional methods described in the Methodology: Manual and Automatic.

To resolve the doubt raised, in this research two experiments were carried out, from which the following analysis is derived.

Comparison of current consumption behaviors with the results of the MAS.

In Graphic 1, with results of the first experiment, it is observed that the MAS obtained an average expenditure much lower than the Automatic method, coming very close to the Manual method which represents the method used for extreme energy savings. 
The MAS spending was also lower than the average consumption of households in the Monterrey Metropolitan Area, indicating that, although the MAS had the resources to spend, it only used what was really necessary; This has been achieved by taking advantage of the idea of Suástegui (2014) on the constant monitoring of consumption and of using the minimum amount of energy required to achieve people's comfort, but in a totally autonomous way.

Contrary to popular belief, it is also surprising to see that the two methods with the lowest cost achieved almost the same comfort for people as the most expensive method, thus indicating that it is not necessary to sacrifice comfort to use less electricity.

The low efficiency of the Automatic method also indicates that reactive automatic devices are capable of providing comfort to people, but they do not have sufficient intelligence to take care of other important aspects such as electricity consumption and, therefore, the economic expense that this implies.

Likewise, it can also be seen that the manual method turned out to be more efficient than the MAS, despite having obtained a slightly lower environmental comfort, therefore, it cannot be said that the MAS has obtained optimal levels in terms of comfort and spending.

\section{Improved MAS results}

Before continuing with the analysis, at this point it is necessary to remember that both the Manual and Automatic methods simulate extreme conditions of human behavior which are very difficult to achieve, that is, in the Manual method, humans will never light a air conditioner, while in automatic mode the air conditioner turns on every time someone enters the room.

Having modeled the controls in the previous way, allows us to have an own appreciation of the range of spending (271 to 4745 Mexican pesos) and environmental comfort (76 to $78 \%$ of comfort) that families in the ZMM can reach using the methods traditional.
To say that the MAS improves electricity consumption with respect to current methods and according to the concept of efficiency presented in this work, the MAS must strictly equal or exceed the value of Environmental Comfort and equal or decrease the expense obtained through another method.

Based on the above, it will be interesting to observe in this last experiment whether the MAS will be able to find better work plans and adapt its behavior to achieve the comfort levels established by current methods, or else, the MAS will simply drop the environmental comfort levels. not having the same budget as in the previous tests.

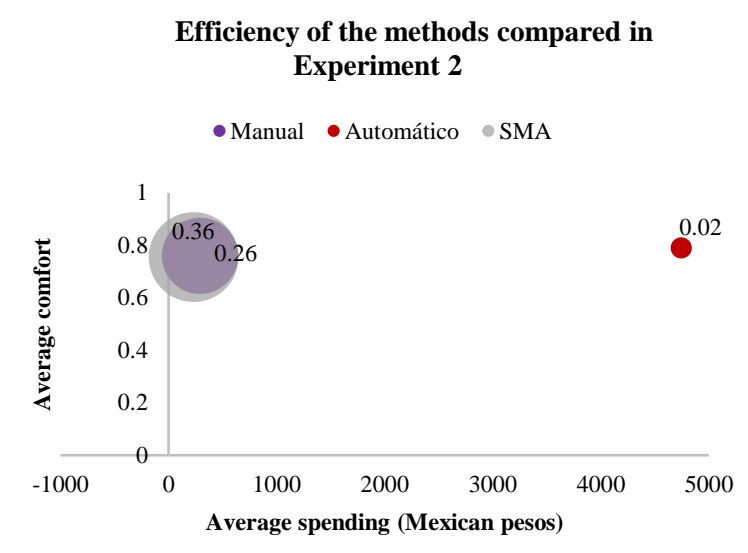

Graphic 2 Comparison between control methods when modifying the MAS parameters

Source: Own elaboration

As can be seen in Graphic 2, with the results of the second experiment, after having reduced the MAS budget in those cases in which this method did not obtain better results, the agents adopted a behavior similar to that of the Manual method, reducing spending opting for new alternatives for air conditioning and lighting the house without lowering the environmental comfort of the inhabitants. Due to the above, the MAS improved the efficiency of its actions, in such a way that it is verified that the MAS will always look for the best solutions according to the working conditions given to it, with the great advantage of operating autonomously. 
With these new results, $66 \%$ is obtained in cases where the MAS reaches Pareto optimality with respect to the manual method, thus increasing the probability of success of using this method not only in homes where the inhabitants have high consumption, but also in places where the inhabitants are already concerned about having low electricity consumption.

\section{Conclusions}

After having observed that the efficiency achieved by the MAS is the highest compared to the other methods and that the experiments were carried out with groups of people with different preferences, it can be stated in the first instance that: the MAS is the best of the three methods to resolve conflicts of interest between people.

Regarding the interest in the rational use of electrical energy, thanks to this research and based on simulated experiments with study groups of homes in the Monterrey Metropolitan Area, it could be shown that:

Monitoring and rational autonomous decisions through MAS are a very good alternative to reduce the consumption of electricity in homes in Mexico.

- It is not necessary to sacrifice the comfort of people to reduce electricity consumption if one has the ability to imitate the intelligent behaviors of humans through autonomous systems.

Of the compared methods, the proposed MASturns out to be the most efficient to provide comfort to people generating the least possible expense.

Given that the MAS is more efficient than the Automatic method in all study groups, and more efficient than the Manual method in $66 \%$ of the cases (based on the Pareto optimality concept), the use of this method is a good alternative as a strategy to generate rational electricity consumption in the Monterrey Metropolitan Area.

\section{References}

Ayala Espino, J. (2004). Mercado, elección pública e instituciones. Una revisión de las teorías modernas del Estado. Ed. Miguel Angel Porrúa y Facultad de Economía-UNAM, México. ISBN 970-701-033-9

Brena, R. F., Handlin, C. W., \& Angulo, P. (2015, October). A smart grid electricity market with multiagents, smart appliances and combinatorial auctions. In 2015 IEEE First International Smart Cities Conference (ISC2) (pp. 1-6). IEEE.

Celik, Berk \& Roche, Robin \& Bouquain, D. \& Miraoui, A.. (2017). Coordinated neighborhood energy sharing using game theory and multiagent systems. 1-6. 10.1109/PTC.2017.7980820.

Centro Nacional de Control de Energía. (2019). Programa de ampliación y modernización de la Red Nacional de Transmisión y de los elementos de las Redes Generales de Distribución que correspondan al Mercado Eléctrico Mayorista (N.o 2019-2033). https://cutt.ly/mfJfPwL.

Coelho, Vitor \& Weiss, Miri \& Coelho, Igor \& Liu, Nian \& Guimarães, Frederico. (2017). Multi-agent systems applied for energy systems integration: State-of-the-art applications and trends in microgrids. Applied Energy. 187. 820832. 10.1016/j.apenergy.2016.10.056.

Denysiuk, Roman \& Lilliu, Fabio \& Vinyals, Meritxell \& Reforgiato Recupero, Diego. (2020). Multiagent System for Community Energy 10.5220/0008914200280039.

Determinantes del consumo de energía eléctrica residencial de la Zona Metropolitana de Monterrey, Nuevo León, en México. Universidad \& Empresa No. 22, pp. 79-98.

Fioretto, F., Yeoh, W., \& Pontelli, E. (2017). A Multiagent System Approach to Scheduling Devices in Smart Homes. AAMAS.

Gerlich, V., \& Zalesak, M. (2010). Experimental validation of heat transfer model. na. 
Instituto Nacional de Estadística y Geografía. (2014). Encuesta Nacional sobre Uso del Tiempo (ENUT) 2014. INEGI. https://www.inegi.org.mx/programas/enut/2014 /default.html\#Microdatos

Instituto Nacional de Estadística y Geografía. (2010). Población en hogares y sus viviendas. Censo de Población y Vivienda 2010.

Mas, A. (2005). Agentes software y sistemas multiagente: conceptos, arquitecturas y aplicaciones. Prentice Hall.

Morales Ramírez, Dionicio; Luyando Cuevas, José Raúl, y Flores Curiel, Daniel (2012).

Morales Ramírez, D. (2015). Actitudes y conocimientos en el consumo de energía eléctrica domiciliaria: caso aplicado a una muestra del área metropolitana de Monterrey, Nuevo León (Doctoral dissertation, Universidad Autónoma de Nuevo León).

Nguyen, T. T., \& Rothe, J. (2013, May). Envyratio and average-Nash social welfare optimization in multiagent resource allocation. In Proceedings of the 2013 international conference on Autonomous agents and multiagent systems (pp. 1139-1140).

Russell, S. (2009). Artificial intelligence: A modern approach author: Stuart russell, Peter Norvig, publisher: Prentice hall pa.

Secretaría de Energía, México. (2010). Ventas internas de energía eléctrica por sector tarifario. SENER | Sistema de Información Energética. http://sie.energia.gob.mx/bdiController.do?actio $\mathrm{n}=$ cuadro\&subAction=applyOptions

Singh, A., Juneja, D., \& Sharma, A. K. (2010, June). Introducing Trust Establishment Protocol in Contract Net Protocol. In Advances in Computer Engineering (ACE), 2010 International Conference on (pp. 59-63). IEEE.

Smith, R. G. (1980). The contract net protocol: High-level communication and control in a distributed problem solver. IEEE Transactions on computers, (12), 1104-1113.
Suástegui, J. (2014). Evaluación del Impacto en el Consumo Eléctrico del Programa de Ahorro Sistemático Integral en Mexicali, Baja California. (Doctorado). Universidad Autónoma de Baja California.

Todaro, M. P., Smith, S. C., (2012). Economic development. Prentice Hall, ISBN-10: 0133406784, ISBN-13: 978-1292002972.

Tutiempo Network, S.L. (2015). Clima en Aeropuerto Internacional Monterrey, N. L. Abril del 2015, de Tutiempo Network, S.L. Sitio web: http://www.tutiempo.net/clima/Aerop_Internaci onal_Monterrey_N_L/763940.htm

Wang, Z., Paranjape, R., Chen, Z., \& Zeng, K. (2019). Multi-agent optimization for residential demand response under real-time pricing. Energies, 12(15), 2867.

Wooldridge, M. (2009). An introduction to multiagent systems. John Wiley \& Sons. 